\title{
Tensile Specimen's Permanent Die Designing and Its Al-Mg Alloy Specimen's Tensile Test
}

\author{
WANG Hongfei ${ }^{1, \text { a }}$, KONG Weibing ${ }^{2, b}$ and HU Xinping ${ }^{3, c}$ \\ ${ }^{1,2,3}$ School of Mechanical Engineering, Qilu University of Technology, Jinan 250353, China \\ a229185496@qq.com, bkongweibing90@163.com, huxxpp@163.com
}

\begin{abstract}
Based on the facts that there are many kinds of metallic tensile specimens with different dimensions, a set of rectangular cross-section and round cross-section tensile specimens are designed according to China national standard GB228-2002 which is called metallic materials' tensile testing at ambient temperature to meet the needs of routine materials researching and testing in factory. According to the designing specimen, a complete set of permanent die was designed and manufactured. Then, Al-Mg alloy was chosen to do the casting processing experiment, and the tensile specimen was obtained and tensile test was finished. It showed that the designing specimen and permanent die met the requirements of tensile test. The round specimen is stronger than the rectangular one and the particles diameter of the studied $\mathrm{Al}-\mathrm{Mg}$ alloy is from $20 \mu \mathrm{m}$ to $50 \mu \mathrm{m}$.
\end{abstract}

Keywords: tensile specimen, permanent die, Al-Mg alloy, tensile test.

\section{Introduction}

The performance of the metal material is mainly composed of yield strength, tensile strength, elongation, and the reliability of the experimental data acquired is not only influenced by experimental condition, but also by the preparation of metal specimens[1]. Metal material performance study cannot be separated from the macro data measuring and microstructure analysis. The mechanical property of metal materials determines the casting's mechanical properties. Mechanical property including mechanical strength, hardness, plasticity, toughness and fatigue strength, which is the inherent properties of materials, and tensile test is one of the methods to obtain the mechanical properties of metallic materials. The main factors affecting the result of the experiment for metal material tensile test are test temperature, specimen size, and shape of the accuracy of experimental equipment, experimental rate, clamping method, data collection, analysis and so on[2]. In scientific research and production practice, due to the varied tension specimen and different sizes, different effects will be produced on the result of the test as well. Li Kai et al studied on the effect of the test results of mechanical properties of metal tensile test that size tolerance, shape tolerance, surface roughness and surface transition arc radius [3].

According to the standards of GB/T 228-2002, this paper designs a set of tensile specimens with rectangular cross-section and round cross-section. According to the design 
of the specimen, we processed and manufactured of a complete set of permanent die which was made of Q350 steel, and choose Al-Mg alloy to do cast experiment to obtain tensile specimen, which was used to the tensile test.

\section{Specimen Design}

According to GB228-2002, casting tensile specimen should meet the two requirements, one is the clamping end and the parallel part should be connected by the arc transition in the casting tensile specimen, the other is that the length of parallel part should be enough. the arc transition's curvature should meet the experimental requirements, the proportion coefficient, metal material products. The shape of clamping end and the test machine chuck in the tensile specimen should be matched. Designing the tensile specimen, the length of the clamping end itself should be long enough so that the distance between the collets position is more than $1.5 \mathrm{~b}$ or $1.5 \mathrm{~d}$. The designed dimension of tensile specimen can be calculated by the data and formula according to standard GB228-2002. The main dimensions of round cross-section tensile specimen and rectangular cross-section tensile specimen were shown in table 1 and table 2 respectively.

TABLE1. THE MAIN DIMENSIONS OF ROUND CROSS-SECTION TENSILE SPECIMEN

\begin{tabular}{ccccc}
\hline Item & Diameter & Original length & Parallel length & Transition arc \\
& $\mathrm{d}$ & $\mathrm{L}_{0}$ & $\mathrm{Lc}$ & radius $\mathrm{r}$ \\
Dim. & 10 & 50 & 66 & 10 \\
$(\mathrm{~mm})$ & & & & \\
\hline
\end{tabular}

TABLE2. THE MAIN DIMENSIONS OF RECTANGULAR CROSS-SECTION TENSILE

\begin{tabular}{ccccc}
\multicolumn{5}{c}{ SPECIMEN } \\
\hline Item & Wide & Original length & Parallel length & Transition arc radius \\
& $\mathrm{b}$ & $\mathrm{L}_{0}$ & $\mathrm{Lc}$ & $\mathrm{r}$ \\
$\operatorname{Dim} .(\mathrm{mm})$ & 12 & 50 & 66 & 12 \\
\hline
\end{tabular}

The permanent die designing is a very complicated work. In older to meet different design requirements, the numbers of die cavity are different, and a plurality of cavity can improve the work efficiency [4]. Usually the tensile testing experiment needs many multiple tensile specimens to carry out a series of complex experiment. They are needed to do assembly, casting, molding, which will increase the experiment time significantly, and the experiment course is also complicated. In addition, the experimental of the rectangular cross-specimen and round cross-specimen could be carry out for the same batch of products. So, they should be produced at the same time. The outcome should be ensured consistent totally in the casting process, and if not form an effective contrast test, this will influence test results and accuracy. Therefore, in the process of die design, the die is designed as a die with two cavities[5].It ensures the round cross-section and rectangular cross-section of the specimen under the same solidification condition, casting in the same environment. Based on the geometry structure of castings, the mold cavity layout was adopted in the form of left to right distribution.

In the design of gating system, based on the simple structure of tensile test specimen, the size and shape are relatively small. The formation of shrinkage of the molten metal occurred at the same time on the solidification stage, and in the last stage of solidification, the feeding liquid metal cannot to enter the solidified parts, and the final solidified areas are 
prone to shrinkage of the solidification [6]. So the sprue with bottom gating system is adopted. In order to meet the control of die temperature in the experimental process, the automatic temperature control system is also amounted in designing the mold overall. A group of power for heating plates of $800 \mathrm{KW}$ is added at both ends of the die so that the die temperature can be controlled in the casting process. And it is controlled according to the temperature value set by the temperature control device. Both sides of the die are wrapped up by asbestos insulation network, which can reduce the loss of die temperature in the heating process, and the temperature control system of die is detected by thermocouple.

\section{Test}

The material of cast specimen we chosen was aluminum magnesium alloy, and the raw material was industrial aluminum with purity of $99.7 \%$, crystalline silicon with the purity of $99.98 \%$ and the high-purity $\mathrm{Mg}$ with the purity of $99.90 \%$. The chemical composition of $\mathrm{Al}-\mathrm{Mg}$ cast specimen was shown in table 3.

TABLE3. CHEMICAL COMPOSITIONS (WT\%) OF THE MATERIALS USED IN THIS STUDY

\begin{tabular}{cccccccc}
\hline Material & $\mathrm{Si}$ & $\mathrm{Mg}$ & $\mathrm{Zn}$ & $\mathrm{Mn}$ & $\mathrm{Ti}$ & Others & $\mathrm{Al}$ \\
\hline AlMg5Si1 & 1.0 & 5.0 & - & - & - & $\leqslant 0.2$ & Allowance \\
\hline
\end{tabular}

$5000 \mathrm{~W}$ well type resistance furnace was adopted to smelt the alloy, and thermocouple electronic temperature control instrument was used to control temperature automatically; The graphite 'crucible was used as a container for melting aluminum magnesium alloy, the crucible wall was brushed two times before melting by titanium dioxide which consists of chalk powder $4 \%$, titanium dioxide $9 \%$, graphite powder $9 \%$, Sodium silicate $7 \%$ and aqueous solvent etc[7]. All the tools for smelting processing in the course of the experiment were made of stainless steel, which was brushed by coating before using. Put the crucible and covering materials into the SX2-2.5-10 box type resistance furnace together, and kept the temperature of $200{ }^{\circ} \mathrm{C}$ for $30 \mathrm{~min}$. Its purpose is to make the material thoroughly dry to water free, to prevent water vapor into the molten aluminum-magnesium alloy, to avoid casting defects in the cast specimen.

Before pouring, preheat the mold to $200^{\circ} \mathrm{C}$ and spread titanium dioxide coating on it so that the coating attached on the surface of the mold evenly, and kept it. The thickness of the coating plays an important role in the process of mold and heat conduction. Changing the thickness of the coating, the flow velocity of the liquid metal and its temperature and die temperature is changing. Slowing the temperature decreasing speed of the casting could avoid liquid metal cooling rapidly[8]. This not only reduces the casting shrinkage porosity rate, but also protects the mold from liquid metal corrosion under high temperature, and the service life of mold could be prolonged.

Si's melting point is $1414^{\circ} \mathrm{C}$, it's difficult to use well type resistance furnace to smelt $\mathrm{Si}$ while melting aluminum-magnesium alloy, so we use induction heating equipment for preparing aluminum-silicon master alloy. The crucible is placed in the well type resistance furnace and the temperature controller is set to $500{ }^{\circ} \mathrm{C}$. After 2 hours' preheating, put the dried aluminum and master alloy into the crucible, sprinkled on the furnace materials with a layer of smelting refining agent, and set the temperature controller to $800^{\circ} \mathrm{C}$. Add the magnesium block wrapped in foil and press them into the liquid alloy after the aluminum silicon alloy is complete melted. Then add the covering agent which is consisted of $\mathrm{KCl}$ and $\mathrm{NaCl}$ to the ratio of $1: 1$. The amount of covering agent should cover all the molten metal. The aim of adding magnesium block wrapped in foil and covering agents is to ensure the isolation of magnesium block from the air in the melting process, to 
reduce the burning loss of magnesium. tools should be clean up, the covering agent and slag should be distributed on the surface of molten alloy evenly. Slag should be avoided to enter into the casting specimen, which could affect the outcome of the trial.

It is appropriate that the mold temperature to be controlled at $220{ }^{\circ} \mathrm{C}$ when casting Aluminum magnesium alloy. Exorbitant temperature of mold will make the specimen's grain size coarsen, and causing serious shrinkage, thermal cracks shrinkage porosity, shrinkage cavity and shorting the service life of mold. However, if the mold temperature is too low, misrun and cold shut could be caused so that the complete specimen could not be obtained. $700^{\circ} \mathrm{C}$ is chosen as casting temperature, and while pouring, slow firstly, then fast, finally slow to avoid entrapping gas in the casting process. First pouring slowly could ensure the liquid alloy enter into the cavity through the runner calmly [9]. When metal filling to a certain extent, it won't feed the casting cavity because of the solidification of gate. In order to avoid the deformation, the tensile specimen should be removed from the die when the casting solidified to certain stage with a strong layer of thin wall. The photo of tensile specimens with gating system is shown in Figure 1. It shows that there are some misruns in the lower corner of the specimen, but these don't influence the specimen's tensile test.

\section{The Tensile Test and the Result Analysis}

The tensile test was carried out on the SANS universal testing machine. Set the experiment parameters and input data before testing referred to the type of the tensile test. PC machine transfers the instructions to the control center and run the test. The load and deformation of the tensile would be feedback to the control center through two different channels by the force sensor and strain gauge. After data processing by the program, the results would be displayed in the PC machine finally.

Tensile aluminum magnesium alloy specimen experiment process is listed as follows: 1) Measure the original length of a same group of casting between the round cross section and rectangular cross section of tensile test specimen with vernier caliper and write down the data in notebook, and make marks on the surface of specimen, then measure the round cross-sectional diameter and rectangular cross-sectional width and thickness, keeping the measurement accuracy of at least $0.01 \mathrm{~mm} .2$ )Input test data and set test parameters, loading of each test specimen, and if the specimen become brittle fractured, stop immediately. 3)At the end of the test, remove the specimens from the tensile testing machine, measuring the length of specimens after fracture, and input the result data into the computer. 4)Save the test data and curve.

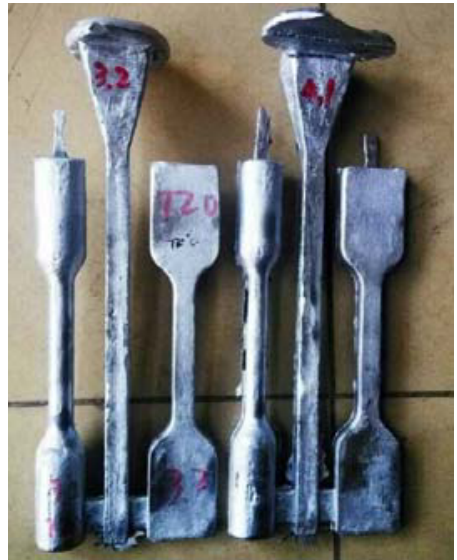

Fig. 1 tensile specimens with gating system 
Then, analysis the data and curve with other software. For the studied Al-Mg alloy round specimens, tensile strength is $182 \mathrm{Mpa}$, and the yield strength is $172 \mathrm{Mpa}$. But for the studied rectangular specimens, the tensile strength and the yield strength is less than $75 \mathrm{Mpa}$. A set of tensile stress-strain curve is obtained and is shown in figure 2. It tells us that the round specimen is stronger than the rectangular one, and it shows no platform in the stress-strain curves. It maybe caused by the different cooling velocity and solidifying velocity of the two kinds specimen. The rectangular specimen solidifying more rapidly, and no much more liquid metal to supplied to the solidifying area, so it become more brittle and weaker than the round one.

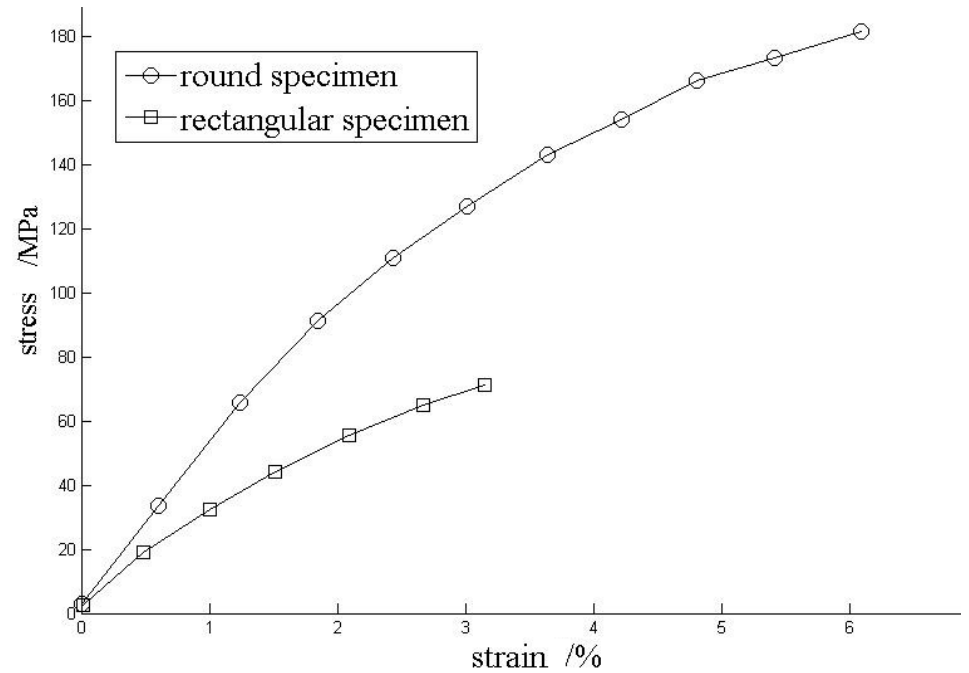

Fig. 2 Force-displacement curve for tensile specimens

The specimen fractured in the position in original length part, which showed that the designed specimen and the permanent die meet the requirement of the tensile test. There is no slag inclusion, pores, shrinkage in fracture when observed with naked eye. In order to observe the microstructure of the fracture, SEM was carried out with Quanta 200, and the specimens' fracture microstructure was shown in figure 3. it is obvious that there were many dimples distributing in the surface of fracture, and the particle was near even with diameter from $20 \mu \mathrm{m}$ to $50 \mu \mathrm{m}$. Contrasting it with typical photomicrograph in some handbook, it could be concluded that it belonged to brittle fracture.

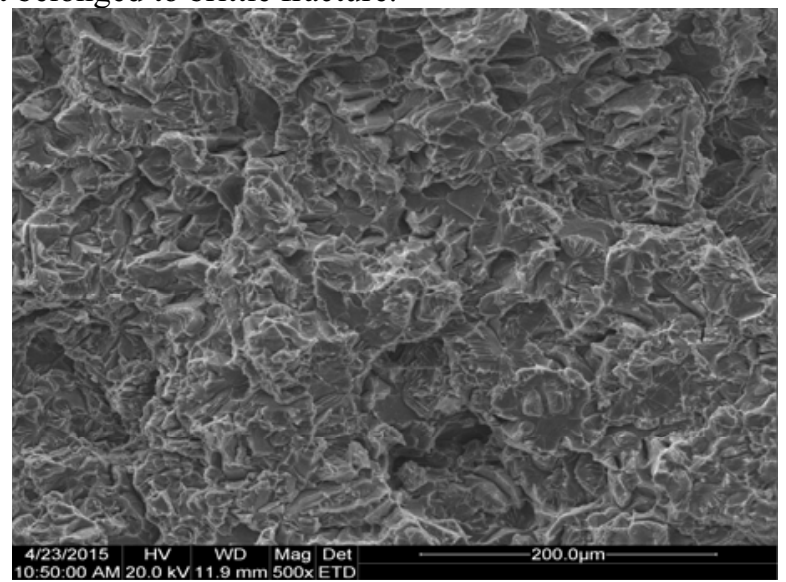

Fig. 3 SEM micrographs of fracture surface of Al-Mg alloy 


\section{Summary}

Based on China national standard GB228-2002 which is called metallic materials' tensile testing at ambient temperature, a set of rectangular cross-section and round cross-section tensile specimens are designed, and a complete set of permanent die was designed and manufactured. It showed that the designing specimen and permanent die met the requirements of tensile test. The round specimen is stronger than the rectangular one and the microstructure of the fracture section showed that the fracture of the specimens belonged to brittle fracture. The particles diameter of the studied Al-Mg alloy was from $20 \mu \mathrm{m}$ to $50 \mu \mathrm{m}$.

\section{References}

1. K. D. Woo, S. W. Kim,Tensile behavior of Al-4 \%Mg-0.4 \%Sc-0.5\%misch metal alloyat room temperature, Metals and Materials International, 11(2005) 95-99.

2. Sun Hongyun, Actors affecting the tensile testing of metallic materials and operational requirements, Modern Measurement and Laboratory Management 6(2008) 27-29.

3. Li Kai, Luan Feng, Influence of machining on the round bar tensile test of metal, Physical Testing 32(2014) 9-10.

4. V. Kumar, J. Madan, P. Gupta, A system for design of multicavity die casting dies from part product model, The International Journal of Advanced Manufacturing Technology 67(2013) 2083-2084.

5. V. D. Shinde, Joshi, B. Ravi, Optimization of mold yield in multicavity sand castings, Journal of Materials Engineering and Performance 22(2013)1574-1581.

6. K. N. Prabhu, K.M. Suresha, Effect of superheat, mold, and casting materials on the metal/mold interfacial heat transfer during solidification in graphite-lined permanent molds, Journal of Materials Engineering and Performance 13(2004)619-626.

7. Chen Yuping, Metal mold gravity casting process of aluminum alloy castings, Casting Technology (2010)1365-1366.

8. A. Hamasaiid, M. S. Dargusch, C. J. Davidson, S. Tovar, Effect of mold coating materials and thickness on heat transfer in permanent mold casting of aluminum alloys, Metallurgical and Materials Transactions A 38(2007) 1303-1316.

9. E. Hajjari, M. Divandari, S. H. Razavi, Microstructure characteristics and mechanical properties of $\mathrm{Al} 413 / \mathrm{Mg}$ joint in compound casting process, Metallurgical and Materials Transactions A 43(2012) 4667-4677. 